\title{
Congenital Lactose Malabsorption
}

\author{
B. LEVIN, J. M. ABRAHAM. E. ANN BURGESS, and PATRICIA G. WALLIS \\ From the Queen Elizabeth Hospital for Children, London, and Children's Hospital, Sydenham
}

\begin{abstract}
Levin, B., Abraham, J. M., Burgess, E. A., and Wallis, P. G. (1970). Archives of Disease in Childhood, 45, 173. Congenital lactose malabsorption. A breastfed female infant is described who developed from the third day of life a severe watery diarrhoea, with weight loss. This ceased when lactose was omitted from the feeds and returned when it was resumed. Intolerance to this carbohydrate was confirmed by a lactose tolerance test which showed inability to hydrolyse the disaccharide. Absorption of glucose and sucrose was normal. No other cause for the diarrhoea was established. Congenital lactose malabsorption (alactasia) was confirmed by examination of the duodenal mucosa. The lactase activity was virtually absent, and the maltase, isomaltase, and sucrase activities were normal. The differential diagnosis of the congenital and acquired forms is discussed, and the importance of intestinal mucosal enzyme assays for final confirmation of the diagnosis is stressed.
\end{abstract}

Since the original description by Holzel, Schwarz, and Sutcliffe (1959) of a condition of failure to thrive in infancy due to malabsorption of lactose, 18 patients with this syndrome have been reported (Holzel, 1967). It was attributed to a congenital isolated deficiency or absence, in the intestinal mucosa, of the enzyme lactase, which hydrolyses lactose into glucose and galactose for the final absorption. Such a congenital and probably inherited deficiency should be confirmed by the quantitative assay of the intestinal mucosa. In only 7 of these patients, however, were direct estimations of the enzyme made, and of these the evidence of an isolated absence of lactase activity was convincing in only 2 where biopsy was performed in infancy.

Intestinal lactase deficiency with histologically normal mucosa occurs relatively frequently in the adult (Haemmerli et al., 1963; 1965). Since symptoms do not date from early childhood, intolerance, in these cases, is generally considered to be acquired. A similar aetiology might conceivably be ascribed to lactose intolerance occurring in infancy. This possibility receives some support from the ease with which intestinal disaccharidase activities are much reduced with injury to the small intestine; in particular, lactase activity is the first to be affected and probably the last to recover (B. Levin, E. A. Burgess, and W F. Young, 1965, unpublished observations).

Received 4 August 1969.
In view of the doubt regarding the occurrence of a hereditary alactasia, it seems important to record all cases that fulfil the criteria of this condition, and in this article we describe a patient who has been observed since birth and in whom duodenal enzyme estimations were made at 14 months of age.

\section{Case History}

A female infant, weighing $3742 \mathrm{~g}$., was delivered at term following a pregnancy which was normal except for the mother's mildy raised blood pressure during the last three months. Breast feeding was begun on the second day of life, explosive watery diarrhoea developed on the next day, and her weight fell to $3400 \mathrm{~g}$. Galactosaemia was suspected and after parenteral fluids for 24 hours, she was given Galactomin, a lactose-free product. Diarrhoea ceased and 6 days later the patient had almost regained her birthweight. The diagnosis of galactosaemia was excluded by a normal erythrocyte galactose uridyl transferase activity, and as there was no further gain in weight, an evaporated milk formula was substituted for Galactomin. This resulted in prompt diarrhoea, which stopped on reverting to Galactomin with added glucose. Lactose intolerance was then considered and confirmed by a lactose tolerance test performed when she was 3 weeks old. This carbohydrate was, therefore, completely excluded from the diet, beginning with Galactomin with added glucose, then sucrose and baby rice, and later a lactose-free mixed diet. She has since thrived and has no gastro-intestinal symptoms. A jejunal biopsy was performed at 14 months of age. At $2 \frac{1}{2}$ years she is a healthy normal child weighing $12.9 \mathrm{~kg}$., i.e. on the 50 th centile. 
Family history. She is the sixth child of normal non-consanguineous parents. Four older sibs (3 brothers and 1 sister) are alive and well, having no history of gastro-intestinal disturbances. Another sister had 'fairly severe' neonatal jaundice for 3 weeks, and died at the age of $5 \frac{1}{2}$ months after protracted episodes of diarrhoea, vomiting, and failure to gain weight. She had been breast fed at first and then the feeds were changed to cow's milk.

\section{Methods}

Carbohydrate tolerance was determined after an overnight fast by estimating blood glucose levels, using a specific glucose oxidase method, after ingestion of 2 g. $/ \mathrm{kg}$. of the disaccharide or $1.75 \mathrm{~g} . / \mathrm{kg}$. of glucose in water. Urinary sugars were shown by paper chromatography. Stools were examined for carbohydrates by direct paper chromatography of the fluid stool, using butanol-acetic acid-water, or isopropyl alcohol-water as solvent systems. Jejunal or duodenal mucosal biopsies were obtained using a Crosby capsule (Crosby and Kugler, 1957), and specimens were examined with dissecting and light microscopes. Lactase, maltase, palatinase, and sucrase activities in the mucosa were measured as described previously (Burgess et al., 1964). Palatinose was used as substrate instead of isomaltose, since it is also hydrolysed by isomaltase.

\section{Results}

Routine investigations. The serum calcium, phosphorus, alkaline phosphatase, protein, electrolytes, and blood urea were all normal. The stools contained no excess fat. Paper chromatography of the urine showed a normal amino acid pattern. No milk antibodies were detected in the serum.

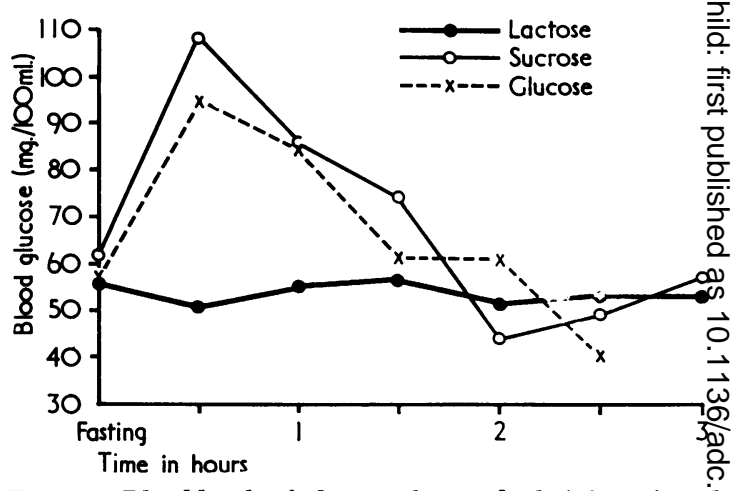

FIG. 1.-Blood levels of glucose after oral administration of carbohydrate $(2 \mathrm{~g} . / \mathrm{kg}$. disaccharide or $1.75 \mathrm{~g} . / \mathrm{kg}$. glucose) in

Carbohydrate tolerance tests. After lactose ha $\vec{P}$ been excluded from the feeds for a week, an oral lactose tolerance test was performed when the infant was $\xi^{j}$ weeks old. There was no rise in blood glucose (Fig. 1)을 Even this single dose of lactose induced diarrhoeaThree stools collected after the test were fluid, offensives and with an acid $p \mathrm{H}$. Paper chromatography reveales. large amounts of lactose. The urine also contained lactose. Glucose and sucrose oral tolerance tests at $2 \frac{1}{2}$ years of age showed normal absorption of these carbohydrates, the blood glucose levels rising to a maximum after 30 minutes. The lactose tolerances repeated at this age gave the same results as in the tese at 3 weeks of age.

Enzyme levels in intestinal mucosa. A biops $\frac{\mathbb{Q}}{B}$ specimen of the 3rd part of the duodenum obtained when the child was 14 months of age showed a norma? histology (Fig. 2). The results of the disaccharidase,

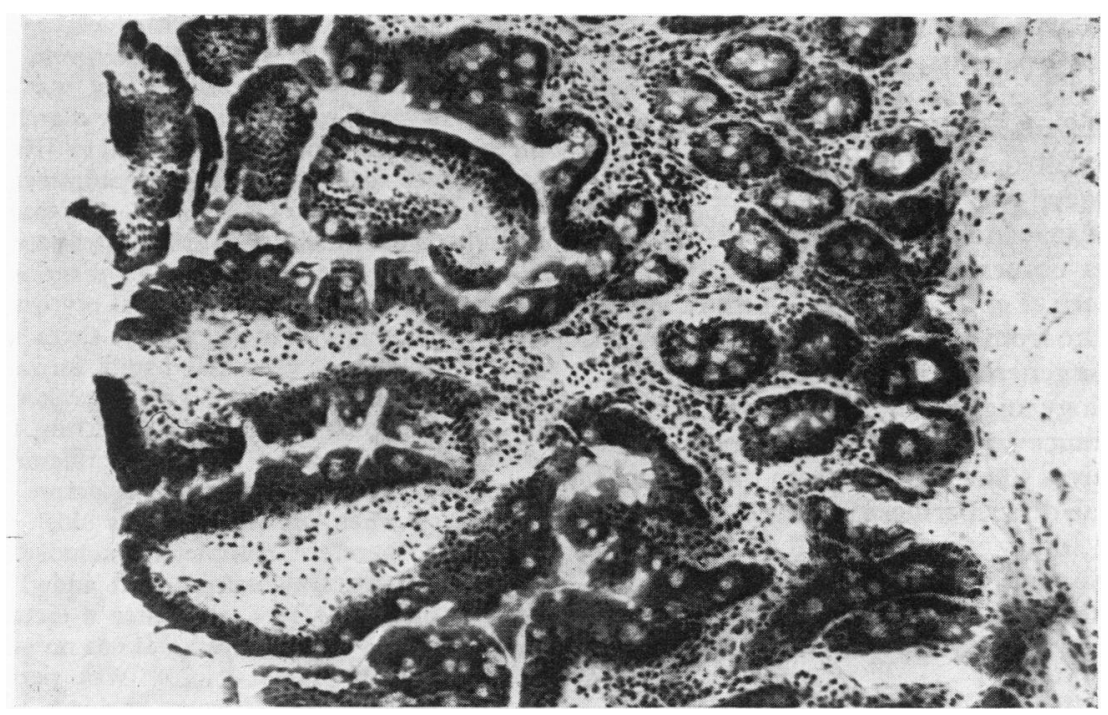

Fig. 2.-Frozen section of duodenal mucosa showing normal villi. (H. and E. $\times 110$. 
assays together with the normal levels for comparison are shown in the Table. There is a virtual absence of lactase activity, but sucrase and isomaltase activities are normal, though there is some decrease in maltase activity.

\section{Discussion}

For the diagnosis of congenital alactasia to be unequivocally established, certain criteria must be fulfilled. Diarrhoea with or without vomiting begins as soon as the infant is given feeds containing lactose, with consequent failure to thrive. Exclusion of lactose from the feeds results in prompt cessation of diarrhoea with resumption of weight gain. The infant is, however, able to absorb dietary carbohydrates other than lactose, as shown by oral tolerance tests, which will also confirm that lactose cannot be hydrolysed and absorbed as glucose and galactose. Other causes of diarrhoea in the neonatal period or later, especially gastro-enteritis, to which lactose intolerance may be secondary, must be excluded. The presence of lactosuria after a lactose load does not differentiate congenital from acquired lactose malabsorption. Finally, together with a mucosa of normal histological appearance, there must be an absent or nearly absent lactase activity of the jejunal or duodenal mucosa, whereas sucrase, maltase, and isomaltase activities are within normal limits.

Previously published cases have usually not conformed to these requirements. In only 2 of the 7 patients in whom mucosal enzyme assays were attempted was there apparently a history of diarrhoea after the first breast-milk feeding (Launiala, Kuitunen, and Visakorpi, 1966). Three were in older children. Thus the $3 \frac{1}{2}$-year-old patient described by Cozzetto (1963) had some, though much reduced, lactase activity, and suffered in addition from cystic fibrosis. Of the other two older children, only scanty details are recorded. One was a 14-year-old girl who presented at puberty for evaluation of growth retardation and was found to have reduced lactase but normal maltase, isomaltase, and sucrase activities of the intestinal mucosa (Sobel et al., 1963; Davidson et al., 1964). The other was a boy of 5 years in whom a biopsy of the third part of the duodenum showed a lactase activity of 5-7 units/g. protein compared with the normal of 31 units (range 10-61 units), and normal maltase, isomaltase, and sucrase activities (Auricchio et al., 1965). Lifshitz (1966) described two patients first seen at 5 and 15 months of age, respectively. The younger one had an absent lactase, and low maltase, isomaltase, and sucrase activities in the jejunal mucosa, but these were only estimated by a semi-quantitative method.
The older child in whom a quantitative assay was performed showed a deficient, but not absent lactase activity.

The two infants recorded by Launiala et al. (1966) were both observed in hospital from the third week of life. Peroral biopsies from the distal duodenum in the 3rd and 5th month of life, respectively, showed no lactase activities in either, when quantitatively assayed. The other disaccharidase activities are within normal limits. These two cases are probably the only children so far reported in whom the diagnosis of congenital alactasia has been conclusively established.

Our patient similarly fulfils the criteria for a diagnosis of congenital lactose malabsorption. While in hospital and within two days of breast feeding she developed watery diarrhoea, loss of weight, and severe dehydration necessitating resuscitation with parenteral fluids. Diarrhoea stopped on omitting lactose from the feeds, and returned when it was resumed. No untoward effects followed the addition of other dietary carbohydrates. There was no evidence of any other cause for the diarrhoea, and this seemed to be due to congenital lactose malabsorption. This was confirmed initially by absorption studies, and later by direct quantitative enzyme activity estimations when the child was 14 months old, and had been on a lactose-free diet during this time. The absence of lactase activity was not due to the prolonged lactose-free diet, since normal lactase activities have been seen in an infant with glucose-galactose malabsorption after a similarly prolonged period of lactose-free diets (Abraham et al., 1967), and was also observed in the case described below. That lactose malabsorption still persisted when she was in the third year of life, with normal absorption of other disaccharides, further supports the conclusion that a congenital defect is present.

Acquired or secondary lactose intolerance frequently occurs in infancy as a result of gastroenteritis, coeliac disease, or injury to the small intestine, and is much more common than the congenital variety. The importance of the estimation of disaccharidase activities in distinguishing the congenital from the acquired conditions is illustrated by the following case history.

\section{Case History}

A full-term male infant weighing $4507 \mathrm{~g}$. at birth failed to gain weight after breast feeding, complemented with evaporated milk from the 2 nd week of life. There were episodes of vomiting from 3 weeks of age, and severe diarrhoea from 5 weeks, requiring intermittent parenteral fluid therapy. No specific causative organism 
TABLE

Disaccharidase Levels (units) in Intestinal Mucosa in Congenital and Acquired Lactose Malabsorption

\begin{tabular}{|c|c|c|c|c|c|c|}
\hline Condition & Biopsy & & Lactase & Maltase & Palatinase & Sucrase \\
\hline $\begin{array}{l}\text { Congenital lactose malabsorption } \\
\text { Normal children } \\
\text { Acquired lactose malabsorption } \\
\text { Normal children }\end{array}$ & $\begin{array}{l}\text { Duodenum } \\
\text { Duodenum } \\
\text { Jejunum } \\
\text { Jejunum }\end{array}$ & $\begin{array}{l}\text { Mean } \pm S D \\
\text { Range } \\
\text { No. } \\
\text { Mean } \pm S D \\
\text { Range } \\
\text { No. }\end{array}$ & $\begin{array}{c}0 \cdot 07 \\
2 \cdot 3 \pm 0 \cdot 5 \\
0 \cdot 2-3 \cdot 5 \\
(7) \\
1 \cdot 9 \\
4 \cdot 9 \pm 0 \cdot 4 \\
1 \cdot 9-9 \cdot 3 \\
(25)\end{array}$ & $\begin{array}{c}5 \cdot 3 \\
15 \cdot 1 \pm 2 \cdot 4 \\
7 \cdot 5-25 \cdot 4 \\
(7) \\
16 \cdot 8 \\
26 \cdot 3 \pm 1 \cdot 8 \\
11 \cdot 8-48 \cdot 4 \\
(25)\end{array}$ & $\begin{array}{c}1 \cdot 6 \\
1 \cdot 3 \pm 0 \cdot 2 \\
0 \cdot 4-2 \cdot 2 \\
(7) \\
2 \cdot 1 \\
2 \cdot 5 \pm 0 \cdot 2 \\
1 \cdot 3-5 \cdot 1 \\
(23)\end{array}$ & $\begin{array}{c}4 \cdot 0 \\
5 \cdot 7 \pm 0 \cdot 9 \\
2 \cdot 2-8 \cdot 7 \\
(7) \\
7 \cdot 6 \\
8 \cdot 9 \pm 0 \cdot 7 \\
4 \cdot 8-19 \cdot 8 \\
(25)\end{array}$ \\
\hline
\end{tabular}

1 unit $=1 \mu$ mole of substrate split per g. mucosa per min.

could be detected in the stools, though Proteus mirabilis was repeatedly isolated. Steatorrhoea was present on some occasions but cystic fibrosis was excluded. Various feeding regimens based on a milk formula were tried without success, and the infant continued to lose weight until at $4 \frac{1}{2}$ months of age, when he weighed no more than his birthweight, Velactin, a soya bean preparation, free of lactose, was substituted for milk. Diarrhoea stopped and he began to gain weight with subsequent thriving on the lactose-free diet. Oral carbohydrate tolerance tests at 6 months showed a failure to hydrolyse both lactose and cellobiose. No diarrhoea followed the lactose dose, but it was induced by the cellobiose load, the fluid stool containing a large amount of this disaccharide. Glucose and sucrose were both normally absorbed. The patient was therefore continued on a lactose-free diet, on which he continued to gain weight and had no intestinal symptoms. However, a peroral jejunal biopsy at the age of 14 months showed normal histology and normal disaccharidase activities, including lactase (Table), thus excluding a diagnosis of congenital malabsorption. Milk was now reintroduced into the diet and caused no ill effect. The origin of this acquired lactose intolerance is obscure but it seems likely that there was an initial episode of severe gastro-enteritis at 5 weeks of age, when diarrhoea was first observed.

Sunshine and Kretchmer (1964) have reported similar instances of infants with acquired intolerance to lactose in whom the capacity to hydrolyse the disaccharide was regained when the diarrhoea ceased, but they offered no corroborative enzyme studies.

Genetics. Though congenital lactose malabsorption is most probably hereditary, final proof is so far lacking. Only 3 pairs of sibs suffering from this condition have been described, but in none have mucosal enzyme levels been estimated. A sib of our patient probably had the same disease. If it is an inherited disorder, the mode of inheritance is uncertain. Only one enzyme study of a parent of an affected child is recorded (Auricchio et al., 1965), and the result was inconclusive. However, byer analogy with congenital sucrose malabsorptionis where such enzyme studies as have been carrieç out support an autosomal recessive inheritance (Burgess et al., 1964), this might be also the case in congenital lactose malabsorption.

We wish to thank Dr. R. H. Dobbs under whose care the second patient was admitted, Dr. Elizabeth Pringle for performing the intestinal biopsies, Dr. N. E. Franceo for the histological examination of the intestinal mucosa and Dr. J. Rawstron for the serum milk antibody test: Thanks are also due to the unfailing help of the nursing staff, in particular Sister R. W. Lucas. One of us (E.A.B.) gratefully acknowledges a grant from the Research Funds of the Queen Elizabeth Hospital fof Children.

\section{RFFERENCES}

Abraham, J. M., Levin. B., Oberholzer, V. G., and Russell, A(1967). Glucose-galactose malabsorption. Archives of Diseas in Childhood, 42, 592.

Auricchio, S., Rubino, A., Prader, A., Rey, J., Jos, J., Frézal, J. and Davidson, M. (1965). Intestinal glycosidase activities in congenital malabsorption of disaccharides. fournal of Pediatrics, 65, 555.

Burgess, E. A., Levin, B., Mahalanabis, D., and Tonge, R. E. (1964)B Hereditary sucrose intolerance: levels of sucrase activity in jejunal mucosa. Archives of Disease in Childhood, 39, 431.

Cozzetto, F. J. (1963). Intestinal lactase deficiency in a patien with cystic fibrosis. Pediatrics, 32, 228.

Crosby, W. H., and Kugler, H. W. (1957). Intraluminal biopsy of small intestine: the intestinal biopsy capsule. American Fournal of Digestive Diseases, 2, 236.

Davidson, M., Sobel, E. H., Kugler, M. M., and Prader, A. (1964)곧. Intestinal lactase deficiency of presumed congenital origin in two older children (Abstr.). Gastroenterology, 46, 737.

Haemmerli, U. P., Kistler, H. J., Ammann, R., Auricchio, S., and Prader, A. (1963). Lactasemangel der Dünndarmmucosa alo Ursache gewisser Formen erworbener Milchintoleranz beinf Erwachsenen. Helvetica Medica Acta, 30, 693.

— - - - Marthaler, T., Semenza, G., Auricchio, S., an Prader, A. (1965). Acquired milk intolerance in the adulb caused by lactose malabsorption due to a selective deficiency of intestinal lactase activity. American fournal of Medicine 38, 7.

Holzel, A. (1967). Sugar malabsorption due to deficiencies of disaccharidase activities and of monosaccharide transport Archives of Disease in Childhood, 42, 341.

, Schwarz, V., and Sutcliffe, K. W. (1959). Defective lactose absorption causing malnutrition in infancy. Lancet, 1, 1126 
Launiala, K., Kuitunen, P., and Visakorpi, J. K. (1966). Disaccharidases and histology of duodenal mucosa in congenital lactose malabsorption. Acta Paediatrica Scandinavica, 55, 257. Lifshitz, F. (1966). Congenital lactase deficiency. Fournal of Pediatrics, 69, 229.

Sobel, E. H., Davidson, M., Kugler, M. M., Zuppinger, K. A., Hsu, L. Y. F., and Prader, A. (1963). Growth retardation associated with intestinal lactase deficiency. (Abstr.) Fournal of Pediatrics, 63, 731.
Sunshine, P., and Kretchmer, N. (1964). Studies of small intestine during development. III. Infantile diarrhea associated with intolerance to disaccharides. Pediatrics, 34, 38.

Correspondence to Dr. B. Levin, Queen Elizabeth Hospital for Children, Hackney Road, London E.2. 